RATIO OF U-232 TO U-233 PRODUCED IN THE TBR.

\section{Lawrence Dresner}

May 23, 1955

\section{Oak Ridge National Laboratory, Tennessee}

\section{LEGAL NOTICE}

This report was prepared as an account of Government sponsored work. Neither the United States, nor the Commission, nor any persan acting on behaif of the Commission:

A. Makes any warranty or representation, express or implied, with respect to the accuracy, completeness, or usefulness of the information contained in this report, or that the use of any information, apparatus, method, or process disclosed in this report may not infringe privately owned rights; or

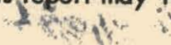

B. Assumes any liabilities with respect to the use of, or for damages resulting from the use of any information, apparatus, method, or process disclosed in this report.

As used in the above, "person acting on behalf of the Commission" includes any employee or contractor of the Commission to the extent that such employee or contractor prepares, handles or distributes, or provides access to, any information pursuant to his employment or contract with the Commission.
Photostat Price $\$ 4.80$

Microfilm Price $\$ 2.70$

Available from the

Office of Technical Services

Department of Commerce

Washington 25, D. C.
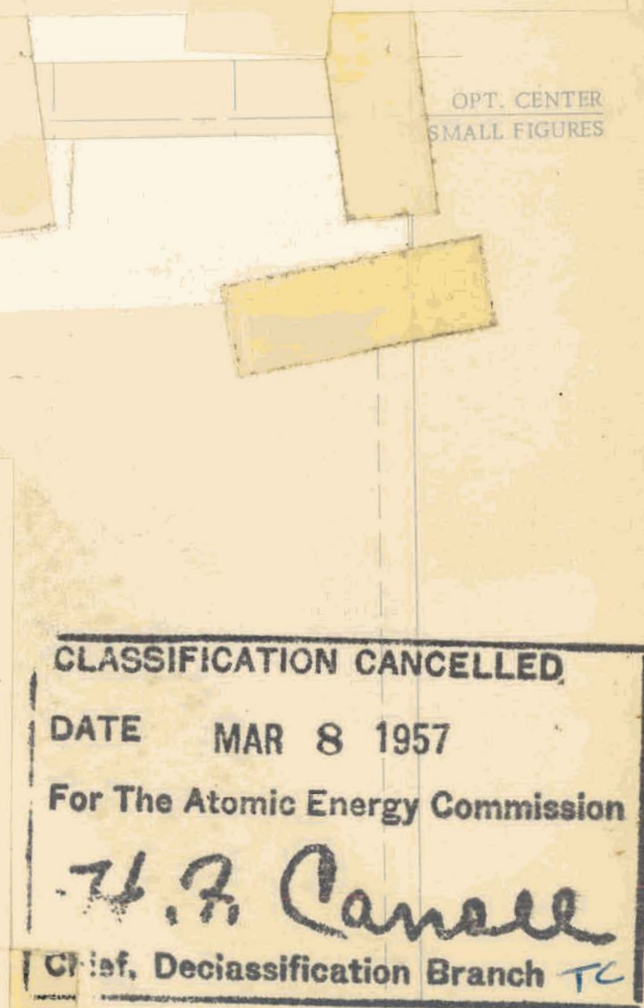


\section{DISCLAIMER}

This report was prepared as an account of work sponsored by an agency of the United States Government. Neither the United States Government nor any agency Thereof, nor any of their employees, makes any warranty, express or implied, or assumes any legal liability or responsibility for the accuracy, completeness, or usefulness of any information, apparatus, product, or process disclosed, or represents that its use would not infringe privately owned rights. Reference herein to any specific commercial product, process, or service by trade name, trademark, manufacturer, or otherwise does not necessarily constitute or imply its endorsement, recommendation, or favoring by the United States Government or any agency thereof. The views and opinions of authors expressed herein do not necessarily state or reflect those of the United States Government or any agency thereof. 


\section{DISCLAIMER}

Portions of this document may be illegible in electronic image products. Images are produced from the best available original document. 


\section{Ratio of U-232 to U-233 Produced in the TBR}

\section{Abstract}

The production of U-232 in the cost optimized TBR and one-region Th oxide-U oxide slurry reactor has been estimated to be, respectively, 40 and 260 parts per million parts of U-233 produced. These production rates are compared with corresponding production rates in irradiated thorium rods and found to be comparable. Recommendations are made for increasing the purity of the U⿻233 product.

\section{Introduction}

In the production of U-233 in nuclear reactors, a small amount of U-232 is produced by the $(n, 2 n)$ reaction on $T h-232$. (1) $U-232$ is the parent of a radioactive decay chain of rather short-lived daughters, some of whose $\gamma$-radiations exceed 2 Mev in energy. Even a minute contamination of U-233 by U-232 produces a deleterious $\gamma$-activity in the U-233 product, but only after several years. This $\gamma$-activity results in a serious radiation hazard.

U-232 decays with a 70-year half-1ife to Th-228; ${ }^{(2)}$ Th-228 decays with a 1.90-year half-life to Ra-224; the remaining decays in this chain, which ends with stable $\mathrm{Pb}-208$, have half-lives of the order of several days or shorter. About $1 / 3$ of the disintegrating atoms of U-232 follow a branch in which a $2.6 \mathrm{Mev}$ $\gamma_{\mathrm{m}}$ ray of T1-208 occurs, and about $2 / 3$ of the atoms follow a branch in which a 2.2 Mev $\gamma-x a y$ of Bi-212 occurs. For a kg of U-233 containing $10 \mathrm{ppm}$ of U-232 (10 $\mathrm{mg}$ ) the activity of all members of the chain after about 2 years is about 0.2 curie. The dose rate at $30 \mathrm{~cm}$ due to this source is about $2.4 \mathrm{r} / \mathrm{hr}$. (3) If the $\gamma$ ray self absorptlor is negligible in the U-233 the minimum safe distance of approach for a 40 -hour week is about $5.4 \mathrm{~m}$; if the $\gamma$-ray self-absorption is as 
high as $75 \%$, the distance of closest safe approach is reduced to $27 \mathrm{~m}$. The dose rate at the surface of a 1 -kg isphere (radius $=2.35 \mathrm{~cm}$ ) is approximately $400 \mathrm{r} / \mathrm{hr}$ if there is no selfmabsorption of the $\gamma$-rays.

Handling of the U-233 product entails no hazard immediately after chemical separation from the fertile thorium. Then the Th-228 concentration small and the activity of remote daughters in the U-232 decay chain is small. After several years, however, a secular concentration of Th-228 is built up, and the U.233 product becomes highly radioactive: Handling must then either be remote or preceded by chemical processing to remove the decay products.

The presence of U-232 causes alpha activity even before secular concentration of the daughter decay products build up. Moreover, the alpha-activity increases as time goes on, eventually including the alpha activities of all the daughters.

It is

the purpose of this report to estimate the production of $\mathrm{U}-232$ in the TBR, and in a one-region Th oxide-U oxide slurry reactor.

\section{Summary of Results; Conclusions}

The ratio of $\mathrm{U}-232$ to $\mathrm{U}-232$ to $\mathrm{U}-233$ produced in the TBR operating under specifications designed to produce minimum cost power to the extent of $100 \mathrm{Mw}$ is estimated at about $40 \mathrm{ppm}$. The ratio of U-232 to U-233 produced in a one-region Th oxidewU oxide slurry reactor designed to produce minimum cost

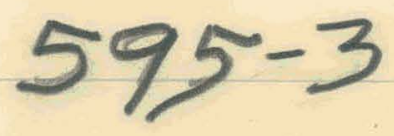


power to the extent of $125 \mathrm{Mw} 1 \mathrm{~s}$ estimated at about $260 \mathrm{ppm}$. In onder to compare the quality of U-233 produced in these reactors with that produced by the irradiation of thorium rods, the ratio of U-232 to U-233 produced was estimated for the irradiation of $2 \mathrm{~cm}$ thorium rods for 6 months in fluxes comparable to those in the homogeneous reactors $\left(\sim 5 \times 10^{13} \mathrm{~cm}^{-2} \mathrm{sec}^{-1}\right)$. The result was about $70 \mathrm{ppm}$. All of these concentrations are sufficiently high to produce a radiation hazard problem after several years.

Several devices can be used in the TBR to decrease the production of U -232 . If the Um233 equilibrium blanket concentration is decreased by more rapid chemical processing, the ratio of fast to thermal flux is decreased. However, such a decrease cannot exceed. about a factor of 10 since at the operating conditions specifled later in this report, about $10 \%$ of the blanket fast flux originates in the core. A rapid chemical processing cycle designed to remove $\mathrm{Pa}$ from the blanket w1ll also decrease the U-232 production by removing the Pa-231. from the neutron flux in the reactor blanket. The rate of production of U-233 will not be affected by such a cycle; the Pa-233 formed merely B-decays outside the blanket. The present chemical process time is about 120 days for the blanket. A decrease to around 10 days for the cycle time on the Pa would accordingly cut by about a factor of 10 the fraction of $\mathrm{Pa}-231$ nuclei undergoing $(n, \gamma)$ reaction. This would of course cut the U-232 production by about a factor of 10. A decrease in flux will also decrease the relative production of U-232 since in its production two neutron reactions rust occur, while only one must occur in the production of U-233. Decreasing the flux, however, has the disadvantage of decreasing the total U-233 production.

It is probable that at best a reduction of two orders of magnitude in the U-232 production can be achieved practically by rapid chemical cycling. 


\section{Production of U-232 and U-233 in the TBR}

In Figure 1 the radioactive chain which leads to production of U-233 and U-232 in the TBR is presented. The half-lives for the varlous nuclear reactions are defined as

$$
T_{1 / 2}=\frac{\ln 2}{\sigma \phi}
$$

where $\sigma$ is the cross section, and $\phi$ the flux. For the $(n, \gamma)$ reactions the thermal flux $\oint_{\text {th }}$ is appropriate; for the $(n, 2 n)$ reaction, on the other hand, the high energy tail $\oint_{f}$ of the flux is appropriate. We can relate the latter to the thermal flux as follows:

We assume that if a high energy neutron makes a single collision with a moderating nucleus, it becomes unavailable for $(n, 2 n)$ reaction. Hence, the number of $(n, 2 n)$ reactions taking place $\mathrm{cm}^{-3} \mathrm{sec}^{-1}$ is given by

$$
\nu^{23} \mathrm{~N}_{23} \sigma^{23}(\mathrm{n}, \mathrm{f}) \phi_{\text {th }} \frac{\mathrm{N}_{02} \sigma^{02}(\mathrm{n}, 2 \mathrm{n})}{\mathrm{N}_{\mathrm{D}_{2} \mathrm{O}} \sigma^{\mathrm{D}_{2} \mathrm{O}(\mathrm{el})}}
$$

where $\sigma^{D_{2} O}(e l)$ is the elastic scattering cross section of $D_{2} O$ at energies around the $(n, 2 n)$ threshold of $T h-232$. Then

$$
\phi_{f}=\nu^{23}\left(\frac{N_{23}}{N_{D_{2}}}\right) \frac{\sigma^{23}(n, f)}{\sigma^{D_{2}}(e l)} \phi_{t h}
$$

- Fission neutrons born in the core which have their first collision in the blanket have been ignored; this neglect will be justified later.

The reaction halfolives in Figure 1 have been calculated for a thermal flux of $5 \times 10^{13} \mathrm{~cm}^{-2} \mathrm{sec}^{-1}$ and a high energy flux of $6.8 \times 10^{12} \mathrm{~cm}^{-2} \mathrm{sec}^{-1}$, which as we shall see later are values appropriate to typical operation of the TBR. The exact equations governing the concentrations of the various members of the 
radioactive chain in equilibrium are cumbersome, and we can simplify them considerably as follows:

When a radioactive nuclide decays in two different ways, the fraction of nuclei following a given branch is inversely proportional to the half-life of that branch: E.g., of the Pa-232 formed in Figure $1, .58 \%$ is destroyed by thermal fission, .041\% is converted to $\mathrm{Pa}-233$ by neutron capture, while the rest, $99.4 \%$, Badecays to II-?3?. We can accordingly simplify our treatment of the radioactive chain by ignoring the fission and capture reactions in Pa-232.

A decay branch appropriate for each nuclide not noted in Figure 1 is removal by chemical processing. The appropriate half-life is the chemical processing cycle time multiplied by $\log$ e2 $(=.693)$. Reasonable cycle times vary from 3 months to a year.

We propose to simplify the decay equations by ignoring: (i) destruction of Th-231 and Th-233 via neutron capture or chemical processing, (11) destruction of Pa-233 via neutron capture, (iii) destruction of Pa-232 via fission, neutron capture or chemical processing. In the case of $T h-231$, the thermal $(n, \gamma)$ cross section is not known, but in order for this branch to compete effectively with $\beta$-decay, the cross section would have to be $\sim 150,000 \mathrm{~b}$, which we assume is not the case. With these simplifications, the decay equations become

$$
\begin{aligned}
& \frac{\mathbb{N}_{02}}{T_{02}(n, 2 n)}=\frac{\mathbb{N}_{11}}{T_{11}(n, \gamma)}+\frac{N_{11}}{T(\text { chem })} \\
& \frac{N_{11}}{T_{11}(n, \gamma)}=\frac{\mathbb{N}_{22}}{T(\text { chem })}+\frac{\mathbb{N}_{22}}{T_{22}(n, \text { total })} \\
& \frac{\mathbb{N}_{02}}{T_{02}(n, \gamma)}=\frac{\mathbb{N}_{13}}{T_{13}(\beta)}+\frac{\mathbb{N}_{13}}{T(\text { chem })} \\
& \frac{\mathbb{N}_{13}}{T_{13}(\beta)}=\frac{N_{23}}{T(\text { chem })}+\frac{N_{23}}{T_{23}(n, \text { total })}
\end{aligned}
$$


Here the T's denote the appropriate half-lives, the N's the concentrations.

Then

$$
\frac{N_{22} / T(\text { chem })}{N_{23} / T(\text { chem })}=\frac{N_{22}}{N_{23}}=\frac{T_{02}(n, \gamma)}{T_{02}(n, 2 n)} \frac{T(\text { chem })+T_{13}(\beta)}{T(\text { chem })+T_{11}(n, \gamma)} \frac{\frac{1}{T(\text { chem })}+\frac{1}{T_{23}(n, t)}}{\frac{1}{T(\text { chem })}+\frac{1}{T_{22}(n, t)}}
$$

This equation is valid for all $\mathrm{T}$ (chem) larger than several days. Typical conditions of operation for the TBR ${ }^{(4)}$ are

$\mathbb{N}_{02}=1000$ gms $/ 1$ (blanket)

$\mathrm{N}_{23}=\quad 3 \mathrm{gms} / 1$ (blanket), $2.51 \mathrm{gms} / \mathrm{kg} \mathrm{D} \mathrm{D}_{2} \mathrm{O}$ (core) $\phi_{\mathrm{th}}=5 \times 10^{13} \mathrm{~cm}^{-2} \mathrm{sec}^{-1}$ (corresponding roughly to $6.2 \mathrm{kw} / \mathrm{l}$ fission
heat in the blanket) Chemical process cycle time $=\frac{120 \mathrm{~d}=.329 \mathrm{y} \text { (blanket) }}{130 \mathrm{~d}=.356 \mathrm{y} \text { (core) }}$

Core radius $=76.2 \mathrm{~cm}$

Blanket radius $=159 \mathrm{~cm}$

Fission heat at core wall $=70 \mathrm{kw} / \mathrm{I}$

Average fission heat in blanket $=6.2 \mathrm{kw} / 1 \quad$ Blanket temp. $=280^{\circ} \mathrm{C}$ The nuclear constants (5) are

$$
\begin{aligned}
& \nu^{23}=2.54 \quad \sigma^{23}(n, f)=533 \text { barns } \quad \sigma^{22}(\text { total })=380 \text { barns } \\
& \sigma^{D_{2} 0}(e 1) \sim 3 \text { barns } \sigma^{02}(n, \gamma)=7.0 \text { barns } \sigma^{13}(n, \gamma)=140 \text { barns } \\
& \sigma^{11}(n, \gamma)=250 \text { barns } \sigma^{23}(\text { total })=585 \text { barns } \sigma^{12}(n, \gamma)=50 \text { barns } \\
& B-1 / 2 \text { life Th-23l }=25.5 \mathrm{~h} \quad \sigma^{12}(\mathrm{n}, \mathrm{f})=700 \text { barns } \\
& \beta-1 / 2 \text { life Th-233 = } 23.5 \mathrm{~m} \quad \sigma^{03}(\mathrm{n}, \gamma)=1400 \text { barns } \\
& \beta=I / 2 \text { Ife } \mathrm{Pa}-233=27.4 \mathrm{~d} \\
& \beta-1 / 2 \text { life } \mathrm{Pa}-232=1.32 \alpha
\end{aligned}
$$


From (3) we have $\phi_{f}=6.8 \times 10^{12} \mathrm{~cm}^{-2} \mathrm{sec}^{-1}$, and thus the half-life of the $(n, 2 n)$ reaction on Th-232 is $2.59 \times 10^{5} \mathrm{y}$. With these contents we find from (5) that

$$
\frac{N_{22}}{N_{23}}=4.0 \times 10^{-5}
$$

Roughly a $30 \%$ decrease in this figure accounts for U-233 recovered from Pa-233 outside the reactor.

It is now necessary to calculate the U-232 production due to fission neutrons born in the core but making their first collisions in the blanket. It is easily shown that if $Q$ monokinetic neutrons are produced $/ \mathrm{cm}^{3}$ on the right side of an infinite wall, the uncollided current $/ \mathrm{cm}^{2}$ to the left at the wall is $Q(\lambda / 4)$, where $\lambda$ is the collision mean free path. Hence the average source of core fission neutrons in the blanket $/ \mathrm{cm}^{3}$ is

$$
\nu^{23}{ }_{N_{23}}^{\text {core }} \sigma^{23}(n, f) \phi_{t h}^{c o r e} \cdot \frac{\frac{1}{4} \lambda \cdot 4 \pi R_{c}^{2}}{\frac{4 \pi}{3}\left(R_{b}^{3}-R_{c}^{3}\right)}
$$

where $R_{b}, R_{c}$ are the blanket and core radil respectively, $\phi_{\text {th }}^{\text {core }}$ is the core thermal flux at the core wall, and $\lambda$ the mean free path in $\mathrm{D}_{2} \mathrm{O}$ corresponding to the cross section $\sigma^{D_{2}}(\mathrm{el})$. The ratio of U-232 produced by core fission neutrons to that produced by blanket fission neutrons is

$$
\frac{N_{23}^{\text {core }}}{N_{23}^{\text {blanket }}} \cdot \frac{P^{\text {core wall }}}{P^{\text {blanket }}} \frac{\frac{3}{4} \lambda R_{c}^{2}}{R_{b}^{3}-R_{c}^{3}}
$$

Here $\mathrm{P}$ denotes thermal fission power density, $\mathrm{P}^{\mathrm{blanket}}$ is an average over the blanket. Using the listed constants, the fraction in (8) is about. equal to 0.1 . Hence we can ignore the contribution of core fission neutrons 
to the U-232 production.

In the above calculation resonance absorption has been consistently neglected. We now propose to investigate the effect this neglect may have on the result (6). The epithermal flux, $\phi(E)$, in a reactor with not too strong resonance absorption is given by

$$
\phi(E)=\frac{q}{\xi \sum_{S}} \frac{I}{E}
$$

where $q$ is the slowing down density, $\xi \sum_{8}$ is the slowing down power of the moderator, and $\mathrm{E}$ the neutron energy. The resonance absorption of species $i$ is then given by

$$
\frac{q}{\xi \sum_{s}} \mathbb{N}_{i} \int \sigma_{a i} \frac{d E}{E} .
$$

where $N_{i}$ is the concentration and $\sigma_{a i} \frac{d E}{E}$ the resonance integral of species 1 . The total thermal absorption equals the thermal slowing down density, which is equal to $\mathrm{q}$ in the event of not too strong resonance absorption. $\mathrm{q}$ times the ratio $N_{1} \sigma_{a 1} t h / \sum_{a}$ gives the thermal absorption rate in species $i$, where $\sigma_{a i}$ th is the thermal absorption cross section of species 1 , and $\Sigma_{a}$ is the macroscopic thermal absorption cross section. The ratio of resonance to thermal absorption in species 1 is

$$
\left(\frac{\sum_{a}}{\xi \sum_{s}}\right) \frac{\int \sigma_{a i} \frac{d E}{E}}{\sigma_{a i} t h}
$$

For $\mathrm{D}_{2} \mathrm{O}, \xi \sum_{\mathrm{s}}=.37 \mathrm{~cm}^{-1},(6)$ in the TBR blanket $\sum_{\mathrm{a}} \sim 10^{-2} \mathrm{~cm}^{-1}$; therefore the first factor is $\sim .03$. If we assume the resonance integral never exceeds much more than 10 times the thermal absorption, then our calculated reaction 
lifetimes are never wrong by more than $\sim 50 \%$ due to neglect of resonance capture, and always err in the direction of being too large. From (5) we can then see that our estimates of U-232 production neglecting resonance neutron capture are reliable, since the ratio $\mathrm{N}_{22} / \mathbb{N}_{23}$ in (5) is relatively insensitive to $50 \%$ changes in reaction Iifetimes.

It is possible for $\mathrm{U}-232$ to be formed also by the $(n, 2 n)$ reaction on either $\mathrm{Pa}-233$ or $\mathrm{U}-233$. If we assume a lifetime of $\mathrm{Pa}-233$ against $(\mathrm{n}, \mathrm{2n})$ reaction about the same as that of Th-232, which is reasonable, then for every atom of U-233 formed by $\beta-$ decay of $\mathrm{Pa}-233$, about $3 \times 10^{-7}$ atoms of $\mathrm{U}-232$ are formed. Thus this mode of production is unimportant. The rate of production of U-232 by the $(n, 2 n)$ reaction on $U-233$ is $\left[.693 N_{23} / T_{23}(n, 2 n) \div\left[1+\frac{T(\text { chem })}{T_{22}(n, \text { total })}\right]\right.$; the rate of production of $\mathrm{U}-233$ is .693 $\mathrm{N}_{23} / \mathrm{T}$ (chem). Then

$$
\frac{N_{22}}{N_{23}}=\frac{T(\text { chem })}{T_{23}(n, 2 n)} / 1+\frac{T(\text { chem })}{T_{22}(n, \text { total })}
$$

which approximately $7 \times 10^{-7}$. Hence both paths contribute only about 2.5 percent of the total U-232 production, and can be ignored.

The use of the $2200 \mathrm{~m} / \mathrm{sec}$ cross section in this calculation ignores the fact that the thermal neutrons are distributed in a Maxwellian distribution with a $280^{\circ} \mathrm{C}$ temperature. The value of the thermal flux derived from the fission rate is then wrong, and for " $\frac{1}{v}$ " cross sections a factor of .645 must be used to correct the cross section, and 1.55 to correct the thermal flux. However, reaction rates, and lifetimes, are exactly the same whether or not the temperature correction is made if all cross sections vary in the same way with energy. Hence the use of the $2200 \mathrm{~m} / \mathrm{sec}$ cross sections is justified. 


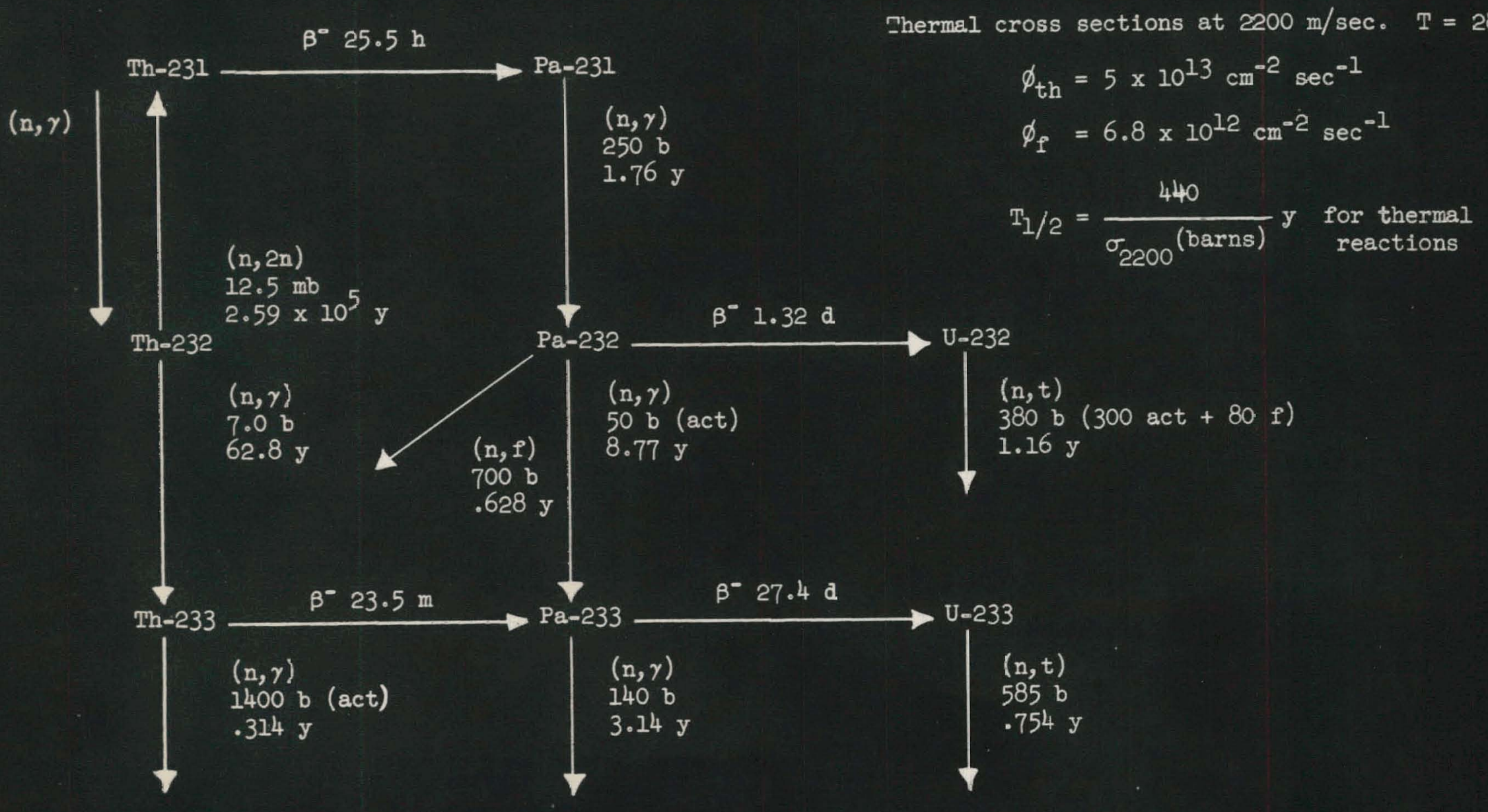

Figure 1 
5. Production of U-232 and U-233 in a One-Region Thorium-Uranium Oxide Slurry Reactor

The method used to analyze the TBR can be used to analyze a one-region thorium-uranium oxide slurry reactor. According to Claiborne ${ }^{(7)}$ the optimum cost reactor of this type has the following specifications (based on a fixed electrical power output of $125 \mathrm{Mw}$ ).

$$
\begin{aligned}
& \text { Reactor diameter }=12 \mathrm{ft} \quad \text { Chemical cycle time }=400 \mathrm{~d} \\
& \text { Thorium concentration }=250 \mathrm{gms} / 1 \\
& \mathrm{U}-233 \text { concentration }=5.82 \mathrm{gms} / \mathrm{kg} \mathrm{D} \mathrm{D}_{2} \\
& \mathrm{U}-235 \text { concentration }=0.56 \mathrm{gms} / \mathrm{kg} \mathrm{D} \mathrm{D}_{2} \\
& \text { Average power density }=18.8 \mathrm{kw} / 1 \\
& \text { Average operating temperature }=280^{\circ} \mathrm{C}
\end{aligned}
$$

The thermal flux corresponding to these specifications is $7.9 \times 10^{13} \mathrm{~cm}^{-2} \mathrm{sec}^{-1}$. Figure 2 presents the decay chain leading to the production of U-232 and U-233, including half-lives calculated from this flux. Proceeding exactly as before, we obtain

$$
\frac{N_{22}}{N_{23}}=2.6 \times 10^{-4}
$$

The reasons why this ratio exceeds that for the TBR are as follows: In the first place, the longer chemical processing cycle time in the one-region reactor results in a greater burnup of U-233 reiative to U-232. This is expressed by the fact that the last factor in (5) Increases as $T(\mathrm{chem})$ increases. Secondly, the longer cycle time results in a greater burnup of $\mathrm{Pa-231}$ relative to $\mathrm{Pa}-233$, which increases U-232 production. This is expressed by the fact that the second factor in (5) increases as $T$ (chem) increases. Finally, the higher concentration of U-233 in the one-region reactor causes a higher ratio 


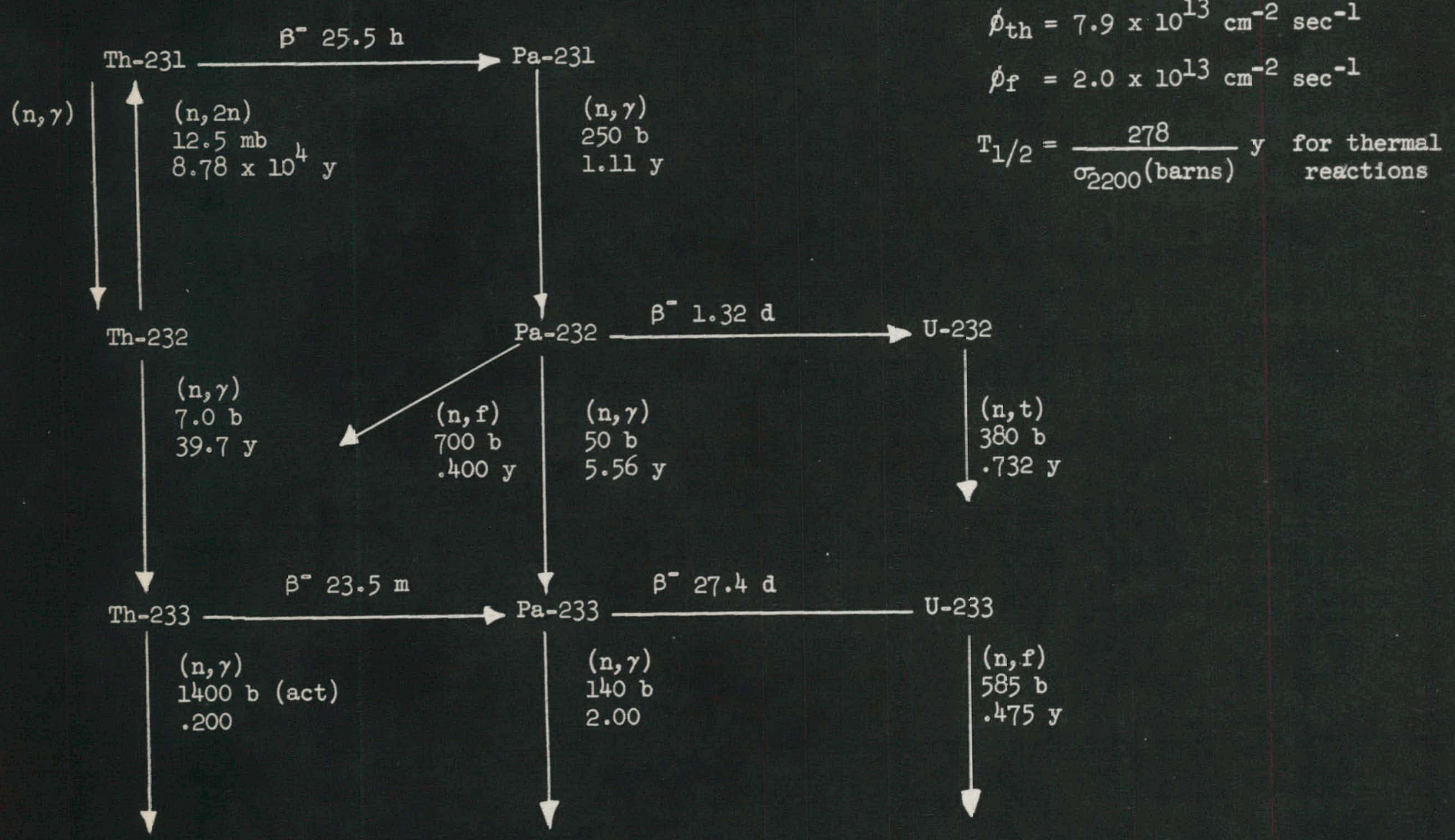

Figure 2 
of $f$ ission to thermal $f l u x$ and increases the relative rate of $(n, 2 n)$ reaction in Th-232. This also increases the U-232 production, as expressed by an increase in the first factor in (5). An additional factor producing more U-232 in the one-region machine is the fact that it is running at a higher flux than the TBR.

\section{The Effect of Heterogeneity in the Fertile Material}

In order to understand the effect of heterogeneity of the fertile material on the production of U-232 let us calculate the ratio of U-232 produced to U-233 produced in a Th-232 rod of $1 \mathrm{~cm}$ radius irradiated in an average thermal flux of $5 \times 10^{13} \mathrm{~cm}^{-?}$ sec-1 for 6 months. In order to simplify the treatment of this problem we make the same assumptions as in section 4 concerning neglect of destruction of Th-231, Th-233, Pa-233 and Pa-232 by neutron absorption. Then the equations governing the decay chain are, for times long compared to the $\beta$-decay half-lives,

$$
\begin{aligned}
& \frac{d N_{11}}{d t}=\text { rate of }(n, 2 n) \text { reaction on Th-232 }-\sigma_{11}(n, \gamma) \phi_{t^{N}} N_{11} \\
& \frac{d N_{22}}{d t}=\sigma_{11}(n, \gamma) \phi_{t h} \mathbb{N}_{11}-\sigma_{22}(n, \text { total }) \phi_{t h} \mathbb{N}_{22} \\
& \frac{d N_{23}}{d t}=\sigma_{02}(n, \gamma) N_{02} \phi_{t h}-\sigma_{23}(n, \text { total }) N_{23} \phi_{t h}
\end{aligned}
$$

The rate of the $(n, 2 n)$ reaction on Th-232 is given by

$$
\nu^{23} N_{23} \sigma_{23}(n, f) \phi_{\text {th }} \frac{\sigma_{02}(n, 2 n)}{\sigma_{02}(n, \text { reaction })} f
$$

where $\sigma_{02}$ (n, reaction) is the reaction cross section of Th-232 at energies $\sim 6 \mathrm{Mev}$, and $\mathrm{f}$ is the fraction of fission neutrons which make any number of elastic collisions in the thorium rod followed by a reaction collision. 
The fraction $f$ may be estimated easily for a slab of thorium infinite in two dimensions and whose thickness equals the rod diameter we wish to consider. This has been done in section 8 , where $f$ is discovered to be $\sim 0.3$.

The solution of equations for $\mathrm{N}_{22} / \mathrm{N}_{23}$ is

$$
\begin{aligned}
& \frac{N_{22}}{N_{23}=\nu^{23}}+\frac{\sigma_{02}(n, 2 n)}{\sigma_{22}(n, \text { reaction })}\left[\frac{\sigma_{23}(n, f)}{\sigma_{22}(n, t)}\left(1-e^{-\sigma_{22}(n, t) \phi t}\right)-\right. \\
& \frac{\sigma_{23}(n, t)}{\sigma_{23}(n, t)-\sigma_{11}(n, \gamma)} \cdot \frac{\sigma_{23}(n, f)}{\sigma_{22}(n, t)-\sigma_{11}(n, \gamma)}\left(e^{-\sigma_{11}(n, \gamma) \phi t}-e^{\left.-\sigma_{22}(n, t) \phi t\right)}+\right. \\
& \frac{\sigma_{11}(n, \gamma)}{\sigma_{23}(n, t)-\sigma_{11}(n, \gamma)} \cdot \frac{\sigma_{23}(n, f)}{\sigma_{23}(n, t)-\sigma_{22}(n, t)}\left(e^{-\sigma_{22}(n, t) \phi t}-e^{\left.-\sigma_{23}(n, t) \phi t\right)}\right) \\
& {\left[1-e^{-\sigma_{23}(n, t) \phi t}\right] }
\end{aligned}
$$

Using the constants quoted above this yields:

$$
\frac{N_{22}}{N_{23}}=7.0 \times 10^{-5}
$$

\section{Cross Sections}

The $(n, 2 n)$ cross section of any nucleus can be written as

$$
\sigma(n, 2 n)=\left.\sigma_{c}(n)\left(1-\frac{\sigma(n, f)+\sigma(n, \gamma)}{\sigma_{c}(n)}\right) \int_{\delta}^{E-E_{t h}} I\left(E^{\prime}, E\right)\left(1-\frac{\sigma(n, f)+\sigma(n, \gamma)}{\sigma_{c}(n)}\right)\right|_{E-E^{\prime}} d E^{\prime}
$$

$\mathrm{E}$ is the energy of the Incident neutron; $\mathrm{E}_{\mathrm{th}}$ is the threshold energy of the $(n, 2 n)$ reaction; $\sigma_{c}(n)$ is the cross section for formation of a compound nucleus 
with a neutron of energy $E ; \sigma(n, f)$ and $\sigma(n, \gamma)$ are respectively the fission and radiative capture cross sections; $I\left(E^{\prime}, E\right)$ is the normalized distribution of product neutrons from the compound nucleus formed with neutrons of energy $\mathrm{E}$.

The first term in (18) is the total reaction cross section, the second term is the non-fission and non-radiative capture probability. The two terms in the integrand tell us respectively the probability that the first neutron emitted leaves behind enough excitation energy to emit a second neutron, and the non-fission and non-radiative capture probability of the intermediate compound nucleus.

For heavy target nuclel, the threshold energy, $\mathrm{E}_{\text {th }}$, is very nearly the neutron binding energy of the target nuoleus ( $r-5-7$ mev). Al these energies $\sigma_{c}(n)=\pi R^{2}$, the geometric cross section of the nucleus. Also for $\mathrm{E} \gtrsim \mathrm{E}_{\text {th }}$, $\sigma(n, \gamma)<<\pi R^{2}$ and $\sigma(n, f)$ varies quite slowly with energy. Finally $I\left(E^{\prime}, E\right)=$ $\theta^{-2} \exp \left(-E^{\prime} / \theta\right)$, where $\theta=(E / a)^{l / 2}$, and a is a constant which varies slowly from nucleus to nucleus (of the same type, e.g., even-even, etc.). (8) Inserting all these equations in (18) we can rewrite it as

$$
\sigma(n, 2 n)=\pi R^{2}\left[1-\frac{\sigma(n, f)}{\pi R^{2}}\right]^{2}\left[1-\left(1+\frac{E-E_{t h}}{\theta}\right) \exp \left(-\frac{E-E_{t h}}{\theta}\right)\right]
$$

Generally it is not the point-by-point value of the $(n, 2 n)$ cross section that will interest us, but the average value with respect to the high energy tail of a pile spectrum above threshold energy. The high energy tail of a pile spectrum has the same energy dependence as the tail of the fission spectrum, viz., (9)

$$
\mathrm{N}(\mathrm{E}) \quad=\mathrm{K} \exp (-\mathrm{E} / \mathrm{c}), \quad \mathrm{C}=1.12 \mathrm{mev}
$$


Compared to the other functions in (19), $\theta$ is a comparatively slowly varying function of E, and in averaging (19) over (20) it will be held constant, and approximately equal to $\left(\mathrm{E}_{\mathrm{th}} / \mathrm{a}\right)^{1 / 2}$. The result of the averaging process is then

$$
\sigma(n, 2 n)=\pi R^{2}\left[1-\frac{\sigma(n, f)}{\pi R^{2}}\right]^{2}\left[\frac{c}{c+\theta}\right]^{2}
$$

For U-238 the constant a can be found. For 14 mev neutrons incident on U-238 the distribution of product (inelastically scattered) neutrons is given by $\theta^{-2} \exp (-E / \theta)$ with $\theta=.72 \mathrm{mev}^{(10)} ;$ a therefore equals $27 \mathrm{mev}^{-1}$. This value is expected to hold also for Th-232. As usual $R=1.45 \mathrm{~A}^{1 / 3} \times 10^{-13} \mathrm{~cm}$, where $A$ is the mass number of the target nucleus. (11) The noutron binding energy can be found from the Weiszacker mass formula ${ }^{(12)}$ and is given by

$$
E_{\text {th }}=M(N-1, Z)+M \text { neutron }-M(N, Z)
$$

where the terms on the RHS of (22) are the masses of nucleus $(\mathbb{N}-1, Z)$, the neutron, and nucleus $(\mathrm{N}, \mathrm{Z})$. For U-238, $\mathrm{E}_{\mathrm{th}}=.0071 \mathrm{amu}=6.6 \mathrm{mev}$. Therefore $\theta=.49$ mev. $\mathrm{R}=9.0 \times 10^{-13} \mathrm{~cm}, \sigma(\mathrm{n}, \mathrm{f}) \simeq .55 \mathrm{~b}$. (13) Hence,

$$
\overline{\sigma(n, 2 n)}=.76 \text { barns } \quad(U-238)
$$

The amount of Watt's fission sepctrum ${ }^{(14)}$ above 6.1 mev is .021 . In view of (20), the amount above $6.6 \mathrm{mev}$ is .013. If we multiply (23) by this last number, we obtain the $(n, 2 n)$ cross section for $U-238$ averaged over the fission spectrum. This result is $10 \mathrm{mb}$. Experiment gives about $9-14 \mathrm{mb}$. (15) Similar calculations for Th-232 gives $E_{t h}=6.7 \mathrm{mev}, \theta=.50 \mathrm{mev}$, $\mathrm{R}=8.9 \times 10^{-13} \mathrm{~cm}, \sigma(\mathrm{n}, \mathrm{f}) \bumpeq .15 \mathrm{~b}$ (16) Hence,

$$
\overline{\sigma(n, 2 n)}=1.05 \text { barns } \quad(T h-232)
$$


The amount of the fission spectrum above $6.7 \mathrm{mev}$ is .012 . The $(n, 2 n)$ cross section of Th-232 averaged over a fission spectrum is then $12.5 \mathrm{mb}$.

A final word is in order concerning the value of $\sigma(n, f)$ appropriate to these calculations. Measured fission cross sections all are known to have a rather sharp step up by about a factor of 2 near the $(n, 2 n)$ cross section. As it turns out the lower value is the more appropriate one. For energies less than the sum of the fission and $(n, 2 n)$ thresholds but somewhat above the fission threshold, the fission cross section is roughly flat. (18) We can then define a figsion branching probability, $G_{f}=\sigma(n, f) / \sigma(n) \bumpeq \sigma_{c}(n, f) / \pi R^{2}$. For energies above the sum of the fission and $(n, 2 n)$ thregholds the fisslun cross section is given by

$$
\sigma(n, f)=\pi R^{2} \cdot G_{f}(E)+\pi R^{2}\left(1-G_{f}(E)\right) \int_{0}^{E-E} I\left(E^{\prime}, E\right) d E^{\prime} \cdot G_{f}^{\prime}\left(E^{\prime}\right)
$$

Here $E_{\text {crit }}$ is the critical fission energy of the target nucleus, and $G_{f}^{\prime}$ is the fission probability of the target (not compound) nucleus. The first term is the cross section for immediate fission, the second the cross section for the emission of a neutron, which leaves behind enough energy to cause a subsequent fission.

$$
\begin{aligned}
\mathrm{E}_{\text {crit }}= & \mathrm{E}_{\mathrm{binding}}+\underset{\text { nission }}{\mathrm{E}_{\mathrm{fin}}}=\mathrm{E}_{(\mathrm{n}, 2 \mathrm{n})}+\mathrm{E}_{\mathrm{fission}} \\
& \text { threshold } \\
\text { threshold } & \text { threshold }
\end{aligned}
$$

Hence, as before,

$$
\sigma(n, f)=\pi R^{2} \cdot G_{f}\left[1+\left(1-G_{f}\right) \frac{G_{f}^{\prime}}{G_{f}}\left(1-\left(1+\frac{E-E_{\text {Crit }}}{\theta}\right) \exp \left(-\frac{E-E_{\text {crit }}}{\theta}\right)\right]\right.
$$

Hence as $\mathrm{E}$ increases past $\mathrm{E}_{\text {crit, }} \sigma(\mathrm{n}, \mathrm{f})$ will increase sharply to the 
constant value

$$
\sigma(n, f)=\pi R^{2} \cdot G_{f}\left[I+\left(I-G_{f}\right) \frac{G_{f}}{G_{f}}\right]
$$

It is clear from this discussion that the value of $\sigma(n, f)$ to be used in the first bracket in (18) is $\pi R^{2} G_{f}$, while that appropriate to the second is $\pi R^{2} G_{f}$. For simplicity we have taken in (18) $G_{f}=G_{f}^{\prime}$.

\section{The f-Factor of Section 6}

The number of neutrons escaping to the right from a unit plane source at $x$ ( 1 neutron per sec per $\mathrm{cm}^{2}$ ) is

$$
\frac{1}{2} \int_{0}^{\pi / 2} \sin \theta d \theta \exp \left(-\frac{\Sigma_{x}}{\cos \theta}\right)
$$

where $\sum$ is the macroscopic total cross section of the slab material. The number escaping to the right from a uniform source inside the slab is then

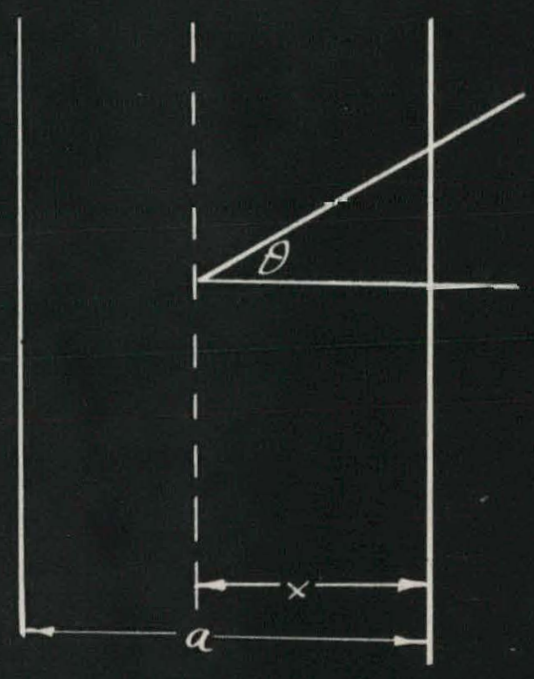

$$
\frac{1}{a} \int_{0}^{a} d x\left[\frac{1}{2} \int_{0}^{\pi / 2} \sin \theta d \theta \exp \left(-\frac{\Sigma_{x}}{\cos \theta}\right)\right]=\frac{1}{2} \frac{1 / 2-E_{3}\left(\Sigma_{a}\right)}{\Sigma_{a}}
$$

where $E_{3}(z)=\int_{1}^{\infty} z^{-3} e^{-Z} d A$. The total number escaping is twice the RHS of (30).

For Th-232, the total cross section at $\sim 6 \mathrm{mev}$ is $\sim 8$ barns. For a $\sim 2 \mathrm{~cm}$ $(=\operatorname{rod}$ diameter $), \Sigma_{a} \sim .50$. Then $1 / 2-E_{3}\left(\Sigma_{a}\right) / \Sigma_{a} \sim 0.56$. Of the $44 \%$ of the source neutrons which make their first collision in the rod, about half of them initiate reactions. This is because at high energies both reaction and scattering cross sections are about equal to the geometric cross section of the nucleus. Of the $22 \%$ which are scattered, about $10 \%$ make second collisions, and 
of these $5 \%$ initiate reactions. Of the remaining $5 \%$, about $2 \%$ make third. collisions, and 1\% react, etc. Hence, roughly $28 \%$ of the source neutrons initiate reactions. This simple estimate assumes that the density of first collisions from a uniform source is also uniform, which is of course not strictly true, but nevertheless a good assumption. Accordingly, we take $f \sim \cdot 3$. 
FOOTNOTES

(1) E. D. Arnold, "Formation of U-232 and the Effects of Its Decay Chain Activity on U-233, Thorium, and the Thorex Process," ORNL-1869, April 4, 1955.

(2) The information on the decay of U-232 in this paragraph is taken from the KAPL "Chart of Nuclides," 4th Edition, November 1952, and from "Nuclear Data," National Bureau of Standards Circular 499, September 1, 1950.

(3) R. Stephenson, "Introduction to Nuclear Engineering, "McGraw Hill, New York, 1954, p. 184.

(4) ORNL-1853.

(5) KAPL, op. cit.; and "Neutron Cross Sections," Brookhaven Neutron Cross Section Compilation Group, BNL-250, August 1, 1954.

(6) S. Glasstone and M. C. Edlund, "The Elements of Nuclear Reactor Theory," Van Nostrand, New York, 1952, p. 146.

(7) H. C. Claiborne, "One-Region Thorium Breeder Reactors," CF-55-3-66, March 11, 1955.

(8) A general reference to the theory in Section 7 is "Theoretical Nuclear Physics," J. Blatt and V. Weisskopf, Wiley and Sons, New York, 1952, Ch. VIII, Section 6.

(9) "Symposium on Fission Physics and Classified Nuclear Physics for Reactors and Shielding," CF-54-10-11, Abstract VII-7, October 13, 1954.

(10) BNL-250.

(11) J. Blatt and V. Weisskopf, Op. cit.

(12) N. Metropolis and G. Reitweisner, "Table of Atomic Masses," NP-1980, Technical Information Service, Oak Ridge, Tennessee, March 1950.

(13) BNL-250.

(14) S. Glasstone and M. C. Edlund, op. cit, p. 64 .

(15) CF-54-10-11, Abstract VII 6 .

(16) BNL-250.

(17) Ibid.

(18) Ibid. 


\section{THIS PAGE \\ WAS INTENTIONALLY LEFT BLANK}

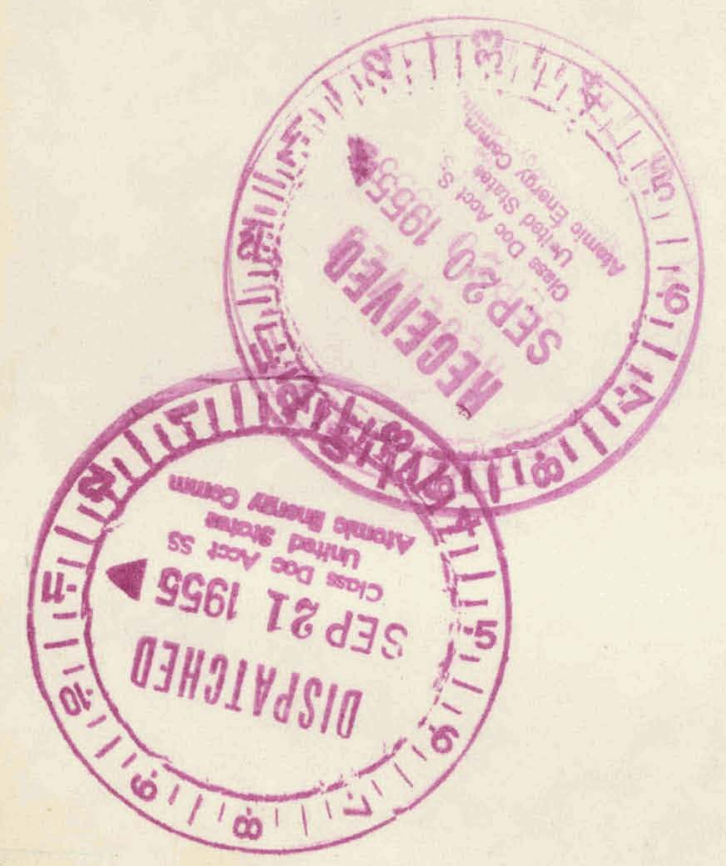

$=$ 